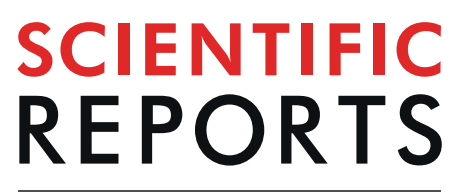

natureresearch

\title{
Reactive oxygen species
} scavenging mechanisms associated with polyethylene glycol mediated osmotic stress tolerance in Chinese potato

\author{
Manas Ranjan Sahoo $\mathbb{1}^{1,3^{*}}$, Tongbram Roshni Devi ${ }^{1,3}$, Madhumita Dasgupta ${ }^{1,3}{ }^{1,3}$ \\ Potshangbam Nongdam² \& Narendra Prakash ${ }^{1}$
}

Influence of polyethylene glycol (PEG) mediated osmotic stress on reactive oxygen species (ROS) scavenging machinery of Chinese potato (Solenostemon rotundifolius (Poir.) J. K. Morton) was investigated. Five genotypes of Chinese potato were raised in Murashige and Skoog (MS) basal medium containing 6-benzylaminopurine (BAP, $1 \mathrm{mg} \mathrm{L}^{-1}$ ) along with various concentrations of PEG-6000 mediated stress conditions $(0,-0.2$ and $-0.5 \mathrm{MPa})$ and evaluated for osmotic stress tolerance in vitro. The medium containing PEG-6000 had a detrimental effect on plantlet growth and development while compared with the control. Accumulation of $\mathrm{H}_{2} \mathrm{O}_{2}$ was lower in Sreedhara and Subala and higher in Nidhi under PEG stress, which was evident by in situ detection in leaves. Lipid peroxidation product such as malondialdehyde (MDA) content was increased due to PEG stress which was more in susceptible genotype than that in tolerant ones. An enhanced ROS-scavenging antioxidant enzyme was observed under stress with respect to the control. The enzymes of ascorbate-glutathione cycle showed an important role in scavenging ROS. The imposition of PEG stress also increased the non-enzymatic antioxidants viz., the ascorbate and reduced glutathione content which was prominent in tolerant genotypes in comparison to susceptible. The present study indicated that, Sreedhara and Subala showed more tolerance to osmotic stress with better ROS scavenging machineries which would be the lines of interest for augmenting future breeding strategies in this climate resilient minor tuber crop.

Chinese potato (Solenostemon rotundifolius (Poir.) J. K. Morton), belongs to the family Lamiaceae, is one of the important minor tuber crops grown in the tropics of the world. The tubers of this crop are rich in carbohydrates and minerals ${ }^{1}$ which provide essential dietary and energy supplements during the lean periods. It could be the better alternative to potato (Solanum tuberosum L.) for the tropics of the world under changing climatic conditions; where potato fails to grow due to global warming. Chinese potato can grow in a wide range of environmental conditions. Despite its wide adaptability, the productivity (18-20 t/ha) was severely affected due to osmotic stress.

Under natural conditions, plant growth and development often challenged by various stresses ${ }^{2}$, of which, osmotic stress is one of the most limiting factors which can cause $20-98 \%$ of yield reductions ${ }^{3}$. To elucidate the plant response to osmotic stress, in vitro cultures are preferred as it minimizes nutrient and environmental variations under control conditions ${ }^{4}$. In this investigation, we have used polyethylene glycol (PEG-6000) to induce osmotic stress conditions in vitro. In plant osmotic stress studies, PEG is widely used as a potential osmoticum in the nutrient medium to induce water deficit ${ }^{5}$.

Induced osmotic stress resulted in overproduction of reactive oxygen species (ROS) which was considered as a hallmark of plant stress response. To scavenge the toxic consequences of ROS, plant deploys antioxidative mechanisms ${ }^{6}$. Oxidative burst led superoxide radicals are dismutated into $\mathrm{H}_{2} \mathrm{O}_{2}$ by superoxide dismutase (SOD). The

${ }^{1}$ ICAR Research Complex for North Eastern Hill Region, Imphal, 795004, Manipur, India. ${ }^{2}$ Manipur University, Canchipur, Imphal, 795003, Manipur, India. ${ }^{3}$ These authors contributed equally: Manas Ranjan Sahoo, Tongbram Roshni Devi and Madhumita Dasgupta. *email: manas.sahoo@icar.gov.in 
liberated $\mathrm{H}_{2} \mathrm{O}_{2}$ is further scavenged by catalase (CAT) and guaiacol peroxidases (GPX). A major $\mathrm{H}_{2} \mathrm{O}_{2}$ detoxifying system operating in plants is also associated with 'ascorbate-glutathione cycle' (ASA-GSH) consisting of four enzymatic antioxidative machineries. In this cycle, ascorbate peroxidase (APX) efficiently manages $\mathrm{H}_{2} \mathrm{O}_{2}$ during stress than CAT. It uses ascorbic acid and oxidizes it to monodehydro ascorbate (MDAR); which gets reduced to regenerate the ascorbate $\operatorname{pool}^{7}$. Similarly, glutathione reductase (GR) converts oxidised glutathione (GSSG) to reduced glutathione $(\mathrm{GSH})^{8}$.

Synthesis of non-enzymatic antioxidants viz., phenolic compounds, ascorbic acid (ASA) and reduced glutathione (GSH) also act as a protective mechanism against oxidative burst. Malondialdehyde (MDA) is one of the lipid peroxidation products indicates ROS induced oxidative damage in plant tissues ${ }^{9}$. The peroxidation of membrane lipids and its role in osmotic stress tolerance in Chinese potato is still unexplored.

Understanding physiological and biochemical mechanisms and ROS scavenging machinery would shed light on inherent stress tolerance potential of plant against adverse conditions ${ }^{10}$. The present study was carried out to investigate ROS scavenging mechanisms in five genotypes of Chinese potato (Solenostemon rotundifolious (Poir.) J. K. Morton) under in vitro PEG mediated oxidative stress conditions.

\section{Materials and methods}

Experimental site and plant materials. This study was carried out at Indian Council of Agriculture Research (ICAR) Research Complex for North Eastern Hill Region, Manipur Centre, Imphal, India during 201516. Five genotypes of Chinese potato viz., Sreedhara, Subala, Nidhi, TVM and CO-1 were used as the source materials for ROS scavenging mechanisms studies under PEG mediated osmotic stress conditions.

Explants, growth conditions, treatments and growth parameters. Nodal explants (5-6 mm) of the five genotypes of Chinese potato were collected from poly house and pre-treated with fungicide (Carbendazim $0.15 \%$ ) for $10 \mathrm{~min}$. The explants were cleaned thoroughly in running tap water, surface sterilized in $2 \%$ sodium hypochlorite solution for $3 \mathrm{~min}$. and rinsed thrice in sterile water. Culture medium included Murashige and Skoog ${ }^{11}$ basal medium with 6-benzylaminopurine (BAP, $\left.1 \mathrm{mg} \mathrm{L}^{-1}\right)$ and sucrose $\left(30 \mathrm{~g} \mathrm{~L}^{-1}\right)$ solidified with phytagel $\left(3 \mathrm{~g} \mathrm{~L}^{-1}\right)$. PEG-6000 at a concentration of 118.0 and $197.0 \mathrm{~g} \mathrm{~L}^{-1}$ was incorporated in MS medium to induce osmotic stress of -0.2 and $-0.5 \mathrm{MPa}$, respectively and $\mathrm{pH}$ was adjusted to $5.8 \pm 1$. Equal amount of culture media ( $15 \mathrm{ml})$ was poured into the test tubes $(25 \times 100 \mathrm{~mm}$, Borosil, India) and sterilized in a steam autoclave (Remi, India) at $105 \mathrm{kPa}$ for $15 \mathrm{~min}$. Nodal explants of all the five genotypes were inoculated in the MS medium with different levels of PEG. The explants inoculated in MS + BAP alone were maintained as the control. All cultures were incubated at $25 \pm 2{ }^{\circ} \mathrm{C}$ with $16 \mathrm{~h}$ photoperiod and $40 \mu \mathrm{mol} \mathrm{m}^{-2} \mathrm{~s}^{-1}$ fluorescence light (Phillips, India) for 6 weeks. The experiment was set up in a $5 \times 3$ factorial completely randomized design (fCRD) replicated thrice with triplicate determinations. Shoot and root proliferation of in vitro plantlets were observed at 6 weeks of inoculation.

Estimation of $\mathrm{H}_{2} \mathrm{O}_{2}$, in situ detection of $\mathrm{H}_{2} \mathrm{O}_{2}$ and lipid peroxidation. $\mathrm{H}_{2} \mathrm{O}_{2}$ content in leaf tissues of Chinese potato under different treatments was estimated following the method of Velikova et al. ${ }^{12}$ by measuring the oxidation product at $390 \mathrm{~nm} . \mathrm{H}_{2} \mathrm{O}_{2}$ was estimated using standard concentrations of $0-100 \mu \mathrm{M}$ and was expressed as $\mu \mathrm{M} \mathrm{g}^{-1} \mathrm{FW}$.

$\mathrm{H}_{2} \mathrm{O}_{2}$ produces a brown stain in plant tissues which is localized by 3,3-diaminobenzidine (DAB) ${ }^{13}$. Vacuum infiltration of whole leaves was done with DAB solution $\left(1 \mathrm{mg} \mathrm{mL}^{-1}\right)$ followed by incubation at dark for $12-16 \mathrm{hrs}$ with mild agitation $(80-100 \mathrm{rpm})$ in a rotating shaker (Tarson, India). The chlorophyll was completely removed from the leaves by treating with ethanol:acetic acid:glycerol (3:1:1) and incubated in the circulating water bath (Thermo Fisher Scientific, USA) at $75^{\circ} \mathrm{C}$. The DAB polymerized reddish-brown spots produced on site of the leaf tissues was photographed by a 10 mega prixel digital camera (Sony, India).

The cellular damage caused by ROS can be estimated by lipid peroxidation of the cell membrane; which is measured in terms of malondialdehyde (MDA) content ${ }^{14}$. MDA content $\left(\mathrm{nM} \mathrm{g}^{-1} \mathrm{FW}\right)$ in the leaves was determined using the extinction coefficient ${ }^{15}$ of $155 \mathrm{mM}^{-1} \mathrm{~cm}^{-1}$.

Determination of antioxidant enzymatic activity. Enzymatic antioxidants (SOD, CAT, GPX, APX, MDAR, DHAR and GR) were estimated from six weeks old in vitro leaf tissues $(0.25 \mathrm{~g})$. The leaf samples were ground into powder using liquid nitrogen and homogenised with $50 \mathrm{mM}$ of extraction buffer $\left(\mathrm{NaPO}_{4}, \mathrm{pH}_{7.8}\right)$ containing ethylenediamine tetra acetic acid (EDTA, $1 \mathrm{mM})$, Triton X-100 (0.1\%), ascorbate $(1 \mathrm{mM})$ and sorbitol $(10 \%)$ and then centrifuged $(15,000 \mathrm{rpm}$ for $20 \mathrm{~min})$ at $4{ }^{\circ} \mathrm{C}$. The supernatants were collected for estimation of antioxidative enzymes.

SOD activities (EC 1.15.1.1) was estimated by measuring the inhibition ability of the nitroblue tetrazolium chloride (NBT) reactions ${ }^{16}$. The unit of SOD enzyme inhibiting 50\% NBT was expressed as $\mathrm{U} \mathrm{g}^{-1} \mathrm{FW}$ of leaf sample. Similarly, CAT activity (EC 1.11.1.6) was determined as the rate of $\mathrm{H}_{2} \mathrm{O}_{2}$ scavenged which was measured by decrease in absorbance at $240 \mathrm{~nm}$. Quantification of CAT activity was performed by its molar extinction coefficient $\left(40 \mathrm{mM}^{-1} \mathrm{~cm}^{-1}\right)$ following the method of Aebi ${ }^{17}$.

GPX activity (EC 1.11.1.7) was estimated observing the production of tetraguaiacol using extinction coefficient $\left(26.6 \mathrm{mM}^{-1} \mathrm{~cm}^{-1}\right)^{18}$. APX activity (EC 1.11.1.1) was assayed by observing the decline in absorbance at $290 \mathrm{~nm}$ due to oxidation of ascorbate and quantified using molar extinction coefficient $\left(2.8 \mathrm{mM}^{-1} \mathrm{~cm}^{-1}\right)^{19}$. MDAR (EC 1.6.5.4) was determined according to the method derived by Hossain and $\mathrm{Asada}^{20}$ and the activity was observed by reduction in absorbance at $340 \mathrm{~nm}$ for $1 \mathrm{~min}$ using extinction coefficient ${ }^{21}$ of $6.22 \mathrm{mM}^{-1} \mathrm{~cm}^{-1}$. DHAR (EC 1.8.5.1) catalyses oxidised ascorbate to ascorbate. Activity of DHAR was measured using extinction coefficient $\left(2.8 \mathrm{mM}^{-1} \mathrm{~cm}^{-1}\right)^{19}$. GR (EC 1.6.4.2) activity was measured following the rate of oxidation of NADPH and quantified using extinction coefficient $\left(6.22 \mathrm{mM}^{-1} \mathrm{~cm}^{-1}\right)^{22}$. All the enzymatic assays were carried out by reading the absorbance using a UV-visible spectrophotometer (Thermo Fisher Scientific, USA). 


\begin{tabular}{|l|l|l|l|l|l|l|l|}
\hline Source & $d f$ & $\begin{array}{l}\text { Days to } \\
\text { sprout }\end{array}$ & $\begin{array}{l}\text { No. of } \\
\text { shoots }\end{array}$ & $\begin{array}{l}\text { No. of } \\
\text { leaves }\end{array}$ & $\begin{array}{l}\text { No. of } \\
\text { roots }\end{array}$ & $\begin{array}{l}\text { Length of } \\
\text { shoots }\end{array}$ & $\begin{array}{l}\text { Length of } \\
\text { roots }\end{array}$ \\
\hline Genotypes & 4 & $37.6^{* *}$ & $5.3^{* *}$ & $30.9^{* *}$ & $16.1^{* *}$ & $1.7^{*}$ & $1.90^{* *}$ \\
\hline PEG & 2 & $212.3^{* *}$ & $8.9^{* *}$ & $28.7^{* *}$ & $57.2^{* *}$ & $13.7^{* *}$ & $3.02^{* *}$ \\
\hline Genotypes $\times$ PEG & 8 & $17.0^{* *}$ & $0.2^{\mathrm{NS}}$ & $2.7^{\mathrm{NS}}$ & $2.9^{*}$ & $0.8^{\mathrm{NS}}$ & $0.02^{\mathrm{NS}}$ \\
\hline Error & 30 & 5.7 & 1.3 & 4.7 & 1.2 & 0.4 & 0.2 \\
\hline
\end{tabular}

Table 1. Two way analysis of variance for growth parameters of Chinese potato genotypes under in vitro PEG mediated osmotic stress conditions in a $5 \times 3$ factorial experiment in complete randomized design (fCRD). $* * *$ and ${ }^{\mathrm{NS}}$ Indicates $p \leq 0.05, p \leq 0.01$ and $p>0.05$, respectively.

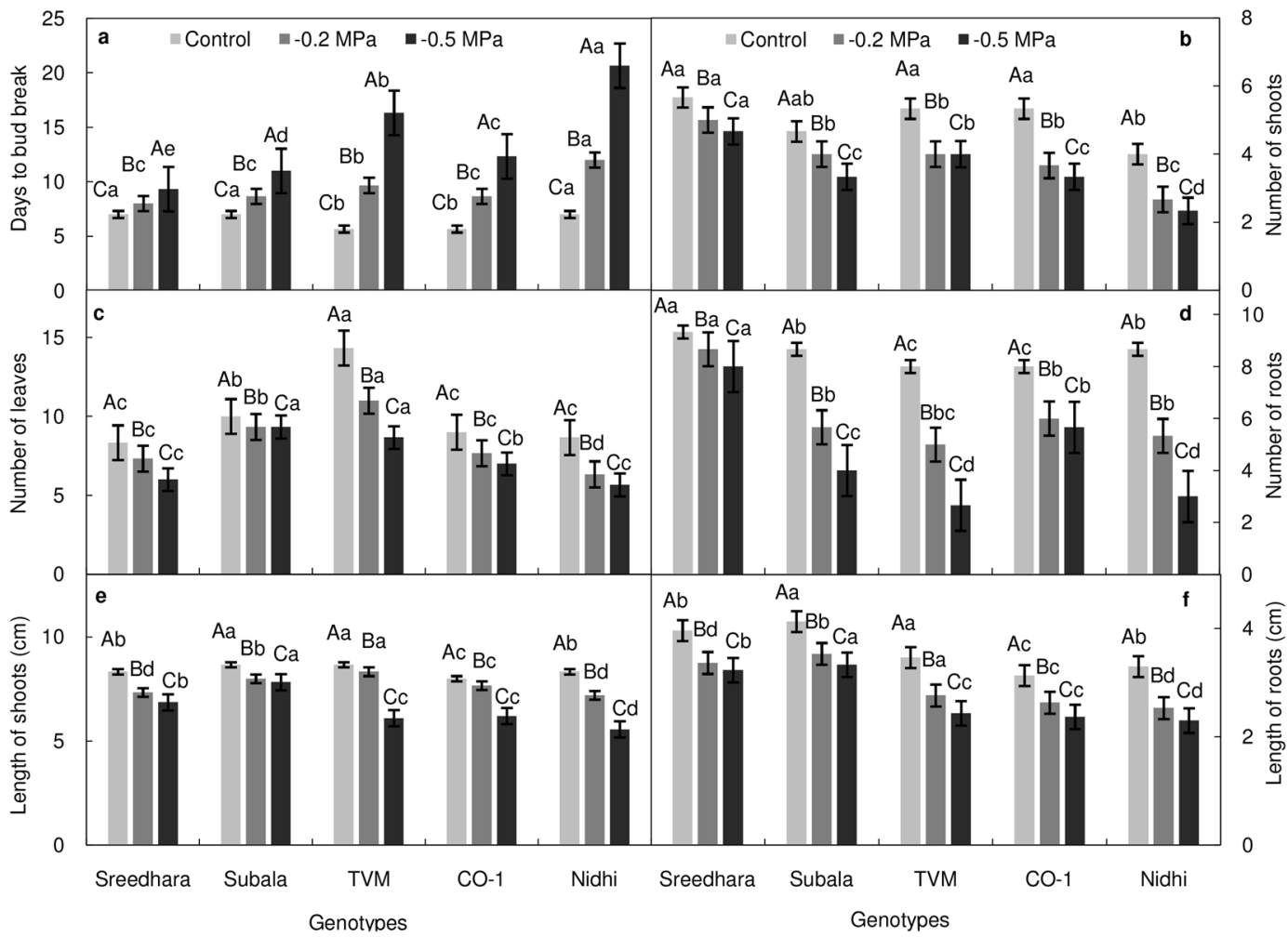

Figure 1. (a-f) Effect of in vitro PEG mediated osmotic stress on growth response of Chinese potato genotypes. (a) days to bud break, (b) number of shoots, (c) number of leaves, (d) number of roots, (e) length of shoots (cm) and (f) length of roots $(\mathrm{cm})$. Values are the mean of three replicates and bars represent standard error of means. Different letters in upper case represent significant differences between the treatments (control, $-0.2 \mathrm{MPa}$ and $-0.5 \mathrm{MPa}$ ) in the genotypes and lower case represents significant difference among the genotypes under each treatment according to Tukey's test.

Determination of non-enzymatic antioxidants: ascorbate (ASA) and reduced glutathione (GSH) content. Ascorbate content (ASA) was estimated following a standard curve plotted with known concentrations of ascorbate in leaf tissue and expressed as $\mathrm{mg} \mathrm{g}^{-1} \mathrm{FW}^{23}$. GSH was estimated following standard method $^{24}$ and quantified using standard concentrations of reduced glutathione ( $\left.\mu \mathrm{mol} \mathrm{g}^{-1} \mathrm{FW}\right)$.

Statistical analysis. Data on in vitro growth parameters, biochemical estimations and ROS scavenging antioxidants were recorded at six weeks of inoculation under control and PEG treatments $(-0.2$ and $-0.5 \mathrm{MPa})$. The experiments were conducted in $5 \times 3$ factorial completely randomized design (fCRD). Analysis of variance (ANOVA ${ }^{25}$ was performed to test the significance at probability level $P \leq 0.05$ and $P \leq 0.01$. Tukey's test was performed to compare significant differences among the mean values ${ }^{26}$. Graphical representations are mean of three replications with triplicate determinations.

\section{Results}

Influence of PEG mediated osmotic stress on in vitro growth responses of Chinese potato. Analysis of variance for in vitro growth parameters (Table 1) showed significant effects across the genotypes and PEG treatments. Growth of in vitro plantlets decreased significantly under PEG treatments $(-0.2$ and $-0.5 \mathrm{MPa}$ ) while compared with the stress-free control. Days to bud break was severely delayed in response 


\begin{tabular}{|l|l|l|l|l|}
\hline Source & $\begin{array}{l}\text { Genotypes } \\
(\mathbf{G})\end{array}$ & PEG $(\mathbf{P})$ & $\mathbf{G x P}$ & Error \\
\hline$d f$ & 4 & 2 & 8 & 30 \\
\hline $\mathrm{H}_{2} \mathrm{O}_{2}$ & $5742.1^{* *}$ & $57120.4^{* *}$ & $2273.7^{*}$ & 582.5 \\
\hline $\mathrm{MDA}$ & $2.621^{* *}$ & $3.670^{* *}$ & $0.315^{\mathrm{NS}}$ & 0.222 \\
\hline SOD & $495.6^{* *}$ & $4103.1^{* *}$ & $188.9^{* *}$ & 34.2 \\
\hline $\mathrm{CAT}$ & $830.8^{* *}$ & $1899.9^{* *}$ & $98.5^{\mathrm{NS}}$ & 126.2 \\
\hline GPX & $15966.7^{* *}$ & $60402.5^{* *}$ & $4789.3^{* *}$ & 17.4 \\
\hline APX & $48852.0^{* *}$ & $46216.0^{* *}$ & $4336.7^{\mathrm{NS}}$ & 1743.2 \\
\hline MDAR & $1920.7^{* *}$ & $3494.6^{* *}$ & $307.8^{\mathrm{NS}}$ & 312.2 \\
\hline DHAR & $283949.8^{* *}$ & $80782.3^{* *}$ & $13127.1^{* *}$ & 3231.3 \\
\hline GR & $17702.1^{* *}$ & $12478.9^{* *}$ & $2469.4^{* *}$ & 609.7 \\
\hline Ascorbate & $1.176^{* *}$ & $1.864^{* *}$ & $0.056^{\mathrm{NS}}$ & 0.029 \\
\hline Reduced glutathione & $1.236^{* *}$ & $36.178^{* *}$ & $3.681^{* *}$ & 0.008 \\
\hline
\end{tabular}

Table 2. Two way analysis of variance for biochemical estimations and ROS scavenging antioxidants of Chinese potato genotypes under in vitro PEG mediated osmotic stress conditions in a $5 \times 3$ factorial experiment in complete randomised design (fCRD). $*, * *$ and ${ }^{\mathrm{NS}}$ Indicates $p \leq 0.05, p \leq 0.01$ and $p>0.05$, respectively.

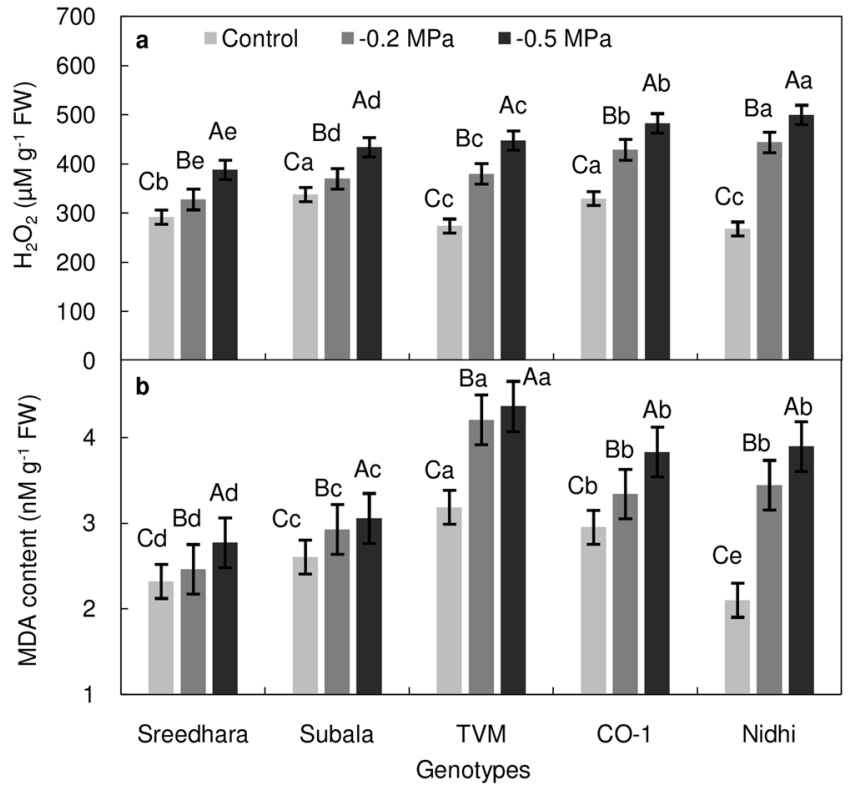

Figure 2. (a-b) Effect of in vitro $\mathrm{PEG}$ mediated osmotic stress on $\mathrm{H}_{2} \mathrm{O}_{2}$ production (a) and lipid peroxidation (b) in leaf tissues of Chinese potato genotypes. Values are the mean of three replicates and bars represent standard error of means. Different letters in upper case represent significant differences between the treatments (control, $-0.2 \mathrm{MPa}$ and $-0.5 \mathrm{MPa}$ ) in the genotypes and lower case represents significant difference among the genotypes under each treatment according to Tukey's test.

to PEG stress (Fig. 1a). After 6 weeks of culture, decrease in number of shoots, leaves, and roots, length of shoots and roots were more pronounced in the higher osmotic treatment $(-0.5 \mathrm{MPa})$ (Fig. $1 \mathrm{~b}-\mathrm{f}, P \leq 0.01)$. Sreedhara and Subala demonstrated less variation in growth parameters than other genotypes under moisture stress as compared to control.

Influence of PEG stress on $\mathrm{H}_{2} \mathrm{O}_{2}$ production, in situ detection and lipid peroxidation of Chinese potato. ANOVA for $\mathrm{H}_{2} \mathrm{O}_{2}$ accumulation and lipid peroxidation (MDA content) revealed significant variation under PEG induced osmotic stress, genotypes and genotype x PEG interactions at $P \leq 0.01$ (Table 2). $\mathrm{H}_{2} \mathrm{O}_{2}$ activity in leaf tissues of Chinese potato was increased with increase in PEG stress (Fig. 2a). Figure 2b represents lipid peroxidation (MDA content) in leaf tissues of control and PEG treated Chinese potato. A significant increment in MDA content was observed among the studied genotypes; which was more in Nidhi than Sreedhara and Subala (Fig. 2b). Figure 3 depicts the in situ detection of ROS through DAB staining in Chinese potato leaves. The PEG treated leaves turned to dark brown which was more pronounced in Nidhi than in Sreedhara and Subala. As expected, the control leaves showed no brown precipitation (Fig. 3). 


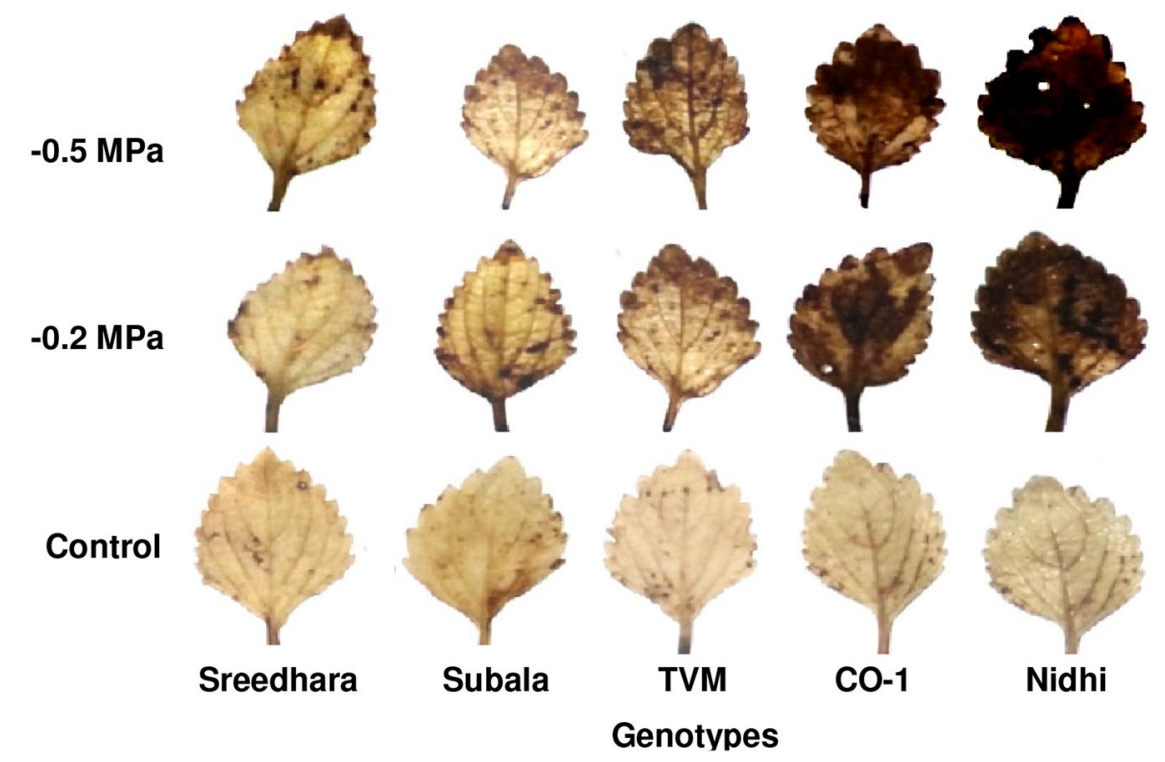

Figure 3. Effect of in vitro PEG mediated osmotic stress on in situ detection of ROS in leaf tissues of Chinese potato genotypes.

Influence of PEG stress on antioxidative enzymes activities of Chinese potato. ANOVA showed significant differences $(P \leq 0.01)$ between the activity levels of ROS scavenging antioxidative enzymes under PEG mediated osmotic stress (Table 2). The activity of all seven antioxidative enzymes increased in Chinese potato leaves when exposed to varying concentrations of PEG stress (Fig. $4 \mathrm{a}-\mathrm{c}$ ). The SOD activity was increased steeply in genotypes Sreedhara and Subala under stress conditions as compared to control (Fig. 4a). Followed by this, the CAT activity showed the similar increasing trend with the increased osmotic stress level (Fig. 4b). The magnitude of increase in CAT activity was highest in Sreedhara (68.50\%), as compared to Nidhi (29.25\%) under higher stress conditions over control. The activity of GPX also significantly increased upon PEG stress (Fig. 4c), being more pronounced in Sreedhara and Subala compared to Nidhi and CO-1.

Influence of PEG stress on ASA-GSH cycle of Chinese potato. The enzymes of ASA-GSH cycle also showed an increment in their activities when imposed to PEG mediated osmotic stress (Fig. 5a-d). Subala registered significantly higher induction of all four enzymes of this cycle viz., APX, MDAR, DHAR and GR; whereas, Nidhi showed the least induction in the similar conditions.

Following PEG imposed stress in leaves, ascorbate (Fig. 5e) and reduced glutathione (Fig. 5f) was increased significantly in all the tested genotypes with respect to their control. Ascorbate content under osmotic stress $(-0.5 \mathrm{MPa})$ was increased to the tune of $83.04 \%$ in Subala followed by $60.08 \%$ in Sreedhara; the same was lower in Nidhi in all the treatments while compared with other genotypes (Fig. 5e). In a similar way, reduced glutathione was increased by 1.63 and 1.14-fold in Subala and Sreedhara, respectively at higher PEG stress as compared to their controls (Fig. 5f).

Overall result implied that the genotypes Sreedhara and Subala performed better under induced PEG stress with the lower accumulation of $\mathrm{H}_{2} \mathrm{O}_{2}$ and MDA which further impaired by induction of various antioxidants (enzymatic and non-enzymatic) as the powerful scavengers of ROS. TVM and CO-1 showed moderately susceptible and Nidhi was characterized as susceptible to moisture stress.

\section{Discussion}

We have taken an in vitro approach to study the effect of PEG mediated osmotic stress on ROS-scavenging mechanisms among five genotypes of Chinese potato. In vitro evaluation is an efficient and quick approach for understanding stress tolerance which showed the similar effect as compared to the labour-intensive field-based screening ${ }^{27}$. So far, there is no report available on effects of PEG mediated osmotic stress on growth responses of Chinese potato in vitro. PEG at high molecular weight acts as a non-intrusive osmotic agent, that overcast the water potential in the culture media and thereby, widely used in osmotic stress tolerance studies in plants ${ }^{28}$. Growth responses of nodal explants of Chinese potato significantly decreased when PEG was incorporated in MS medium. The first detrimental effect of PEG in the shoot multiplication media was evident by a gradual delay in bud break from lower to higher stress as compared to the control. The bud break was earlier by 10 days of inoculation in Sreedhara and Subala, whereas, it was delayed by 3 weeks in Nidhi at $-0.5 \mathrm{MPa}$ stress. The overall growth in terms of number of leaves, number of shoots, length of shoots and rooting was highly affected due to PEG imposed media as compared to the control. Under PEG stress condition, Subala and Sreedhara maintained the growth by registering up to $20 \%$ decrease in shoot proliferation and rooting, which reflects its inherent tolerance towards osmotic stress. On the contrary, Nidhi showed an indication of susceptibility towards PEG stress by exhibiting more growth retardation in vitro. Our previous studies in taro, a carbohydrate-rich tuber crop, demonstrated the detrimental effect of PEG on shoot proliferation in vitro ${ }^{29}$. Reports have also shown that limited 


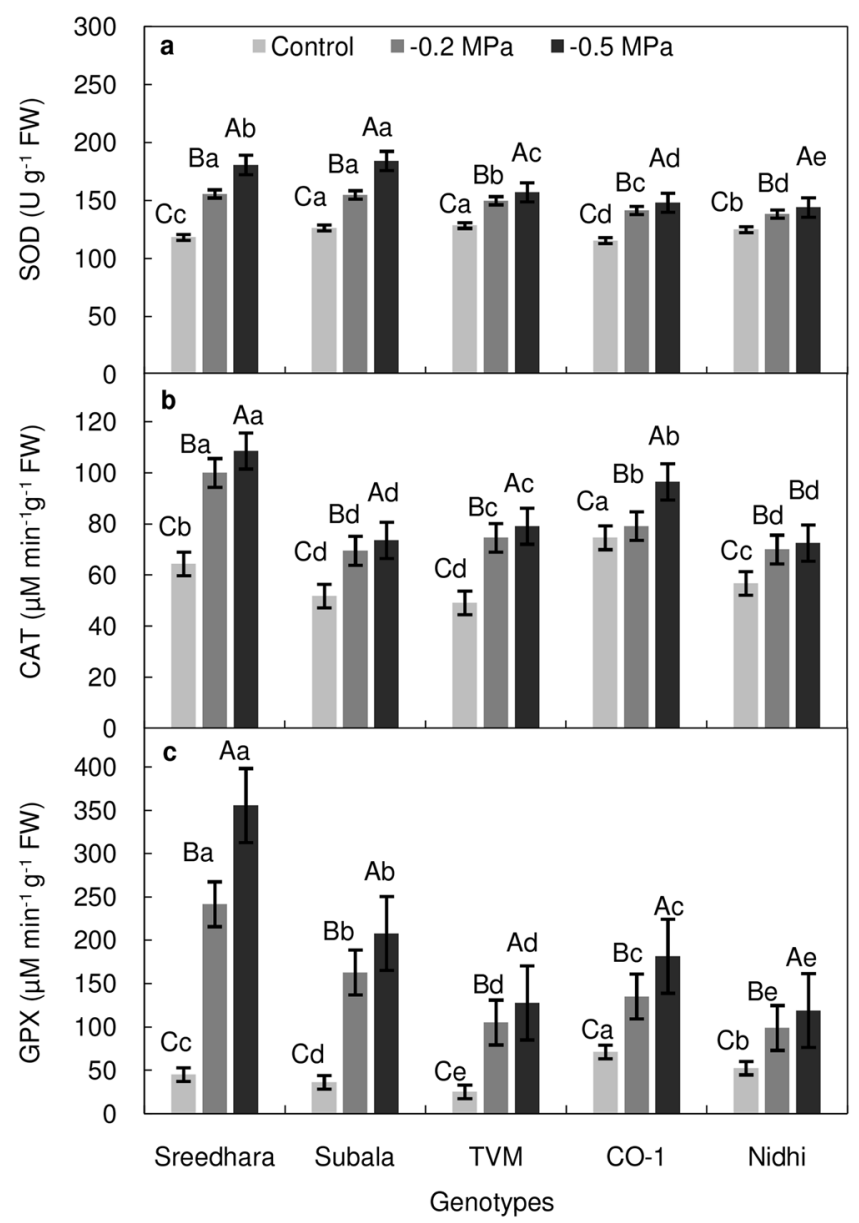

Figure 4. (a-c) Effect of in vitro PEG mediated osmotic stress on antioxidative enzyme activities of leaf tissues of Chinese potato genotypes. (a) superoxide dismutase (SOD, $\mathrm{U} \mathrm{g}^{-1} \mathrm{FW}$ ), (b) catalase (CAT, $\mu \mathrm{M} \mathrm{min}{ }^{-1} \mathrm{~g}^{-1} \mathrm{FW}$ ) and (c) guaiacol peroxidase (GPX, $\left.\mu \mathrm{M} \mathrm{min} \mathrm{mi}^{-1} \mathrm{FW}\right)$, Values are the mean of three replicates and bars represent standard error of means. Different letters in upper case represent significant differences between the treatments (control, $-0.2 \mathrm{MPa}$ and $-0.5 \mathrm{MPa}$ ) in the genotypes and lower case represents significant difference among the genotypes under each treatment according to Tukey's test.

water availability restricted cell division and elongation and thereby hinders plant growth and development ${ }^{30,31}$. The extent of plant growth inhibition depends on the genotype and the severity of stress; which was prominent in our study across the studied genotypes.

ROS generated inside the cell as a result of oxidative stress can target the lipid membranes resulting in elicitation of the lipid peroxidation ${ }^{31,32}$. Increased MDA content is considered as a hallmark of membrane lipid peroxidation and also an indicator of free radical prevalence in the tissues. To understand whether PEG mediated osmotic stress results in the induction of ROS in Chinese potato, we have measured the level of $\mathrm{H}_{2} \mathrm{O}_{2}$ and MDA content in control and stressed leaves. Our results have shown a significant increment in both $\mathrm{H}_{2} \mathrm{O}_{2}$ and MDA content; which shows the involvement of oxidative stress incurred by imposing to PEG stress among the studied genotypes. Sreedhara and Subala registered lower $\mathrm{H}_{2} \mathrm{O}_{2}$ and MDA accumulation (up to 20\%) at higher PEG $(-0.5 \mathrm{MPa})$ as a sign of lower osmotic imbalance. However, Nidhi possessed higher osmotic imbalance with higher accumulation of $\mathrm{H}_{2} \mathrm{O}_{2}$ and MDA (up to 85\%) than its control. In support of our results, Fu et al. ${ }^{33}$ have shown that MDA content of cassava exhibited a linear change under higher PEG treatments. Studies have shown that MDA content and $\mathrm{H}_{2} \mathrm{O}_{2}$ accumulation was about two to four-fold in susceptible genotypes than the tolerant ones ${ }^{34-36}$. From our studies, it was evident that Sreedhara and Subala maintained lower $\mathrm{H}_{2} \mathrm{O}_{2}$ and MDA content irrespective of PEG doses which reflect more membrane stability and also an indication of early defense to combat osmotic stress imposed by PEG.

To further confirm, we have also carried out in situ detection of $\mathrm{H}_{2} \mathrm{O}_{2}$ in leaves by DAB staining. $\mathrm{H}_{2} \mathrm{O}_{2}$ along with peroxidases (a haem-containing protein) oxidizes DAB, which is visualized by a dark brown precipitation in the leaves. Among the genotypes, Nidhi followed by CO-1 showed extensive dark stained DAB sites in the leaves making the leaves turning completely black which is correlated with higher accumulation of $\mathrm{H}_{2} \mathrm{O}_{2}$ compared to Subala and Sreedhara (where only leaf edges were stained). Chakraborty and Pradhan ${ }^{35}$ documented higher accumulation of $\mathrm{H}_{2} \mathrm{O}_{2}$ was associated with the appearance of darkly stained DAB spots in leaves of susceptible varieties of wheat than the tolerant ones; which is in support of our results. Oxidative burst in leaf tissues through 


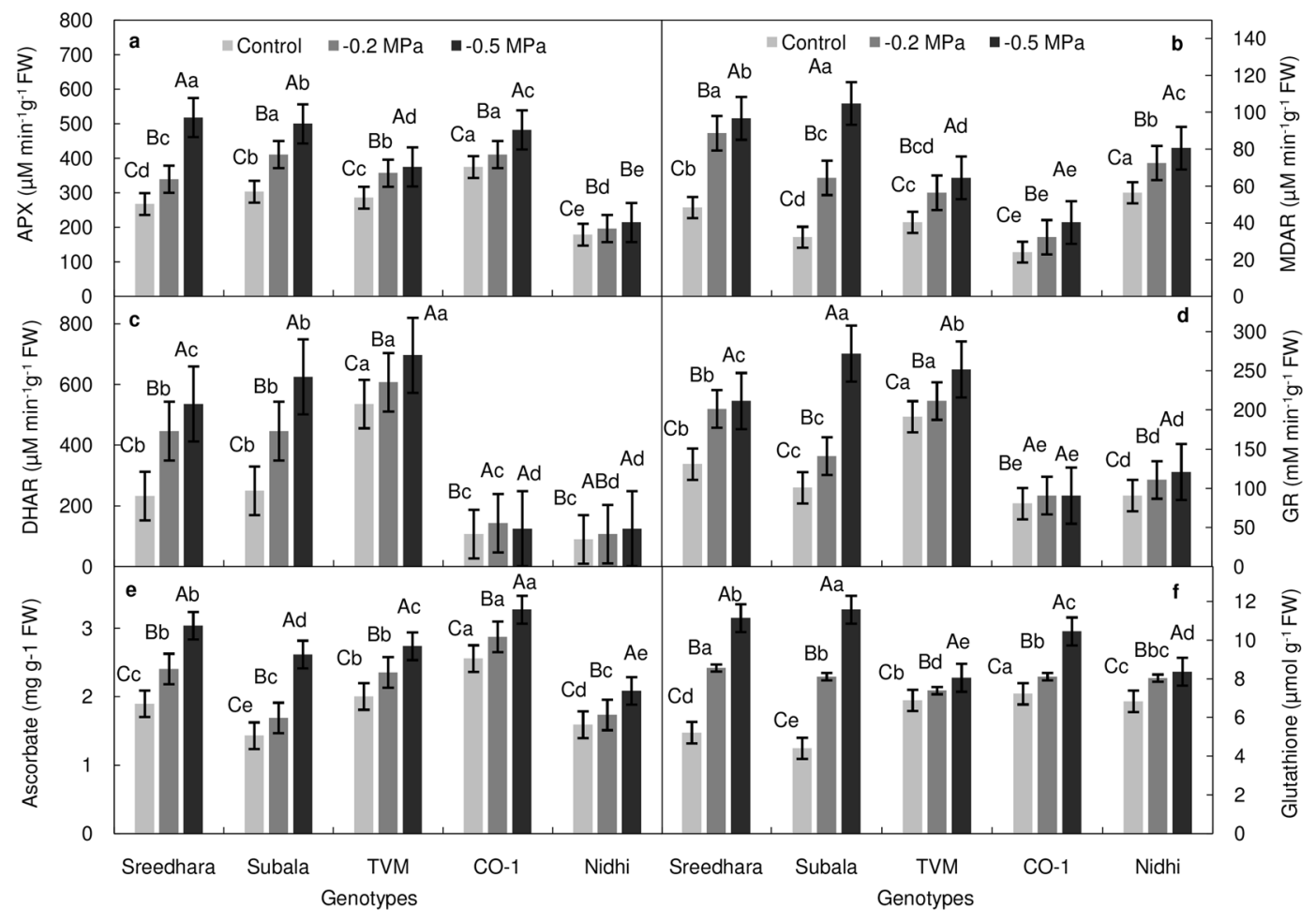

Figure 5. (a-f) Effect of in vitro PEG mediated osmotic stress on ASA-GSH cycle of Chinese potato genotypes. (a) ascorbate peroxidase (APX, $\mu \mathrm{M} \mathrm{min} \mathrm{mi}^{-1} \mathrm{FW}$ ), (b) monodehydro ascorbate reductase (MDAR, $\mu \mathrm{M} \mathrm{min} \mathrm{m}^{-1} \mathrm{~g}^{-1}$ FW), (c) dehydro ascorbate reductase (DHAR, $\mu \mathrm{M} \mathrm{min}^{-1} \mathrm{~g}^{-1} \mathrm{FW}$ ), (d) glutathione reductase ( $\mathrm{GR}, \mathrm{mM} \mathrm{min}^{-1} \mathrm{~g}^{-1}$ $\mathrm{FW}$ ), (e) ascorbate (ASA, $\left.\mathrm{mg} \mathrm{g}^{-1} \mathrm{FW}\right)$, and (f) reduced glutathione ( $\left.\mathrm{GSH}, \mu \mathrm{mol} \mathrm{g^{-1 }} \mathrm{FW}\right)$. Values are the mean of three replicates and bars represent standard error of means. Different letters in upper case represent significant differences between the treatments (control, $-0.2 \mathrm{MPa}$ and $-0.5 \mathrm{MPa}$ ) in the genotypes and lower case represents significant difference among the genotypes under each treatment according to Tukey's test.

formations of free radicals due to PEG stress was characterized by increased ROS production as reflected by a sharp increase in $\mathrm{H}_{2} \mathrm{O}_{2}$ production and also, increased level of MDA. This holds true in the in situ DAB test for ROS generation; where the more extensive brown stain was detected in Nidhi leaves than that of Subala and Sreedhara.

The ability of the fast and effective antioxidant response in stress situations can reflect the stress tolerance ability of the plant ${ }^{37}$. In our study, activities of all antioxidative enzymes were significantly increased under osmotic stress across the Chinese potato genotypes which were higher in Subala and Sreedhara as compared to other genotypes. Khanna-Chopra and Selote ${ }^{38}$ reported a higher level of antioxidative machineries in stressed plants over non-stressed plants. Similarly, Wang et al. ${ }^{39}$ reported that the osmotic adjustment ability in tolerant cultivar is more efficient over susceptible ones. SOD is the first line of antioxidant which rapidly scavenges $\mathrm{O}_{2}{ }^{-}$and restricts the production of $\mathrm{OH}^{40}$. We have observed upto $52.6 \%$ increase in the activity of SOD in Sreedhara followed by Subala $(45.6 \%)$ over control, suggesting that these genotypes have inherent $\mathrm{O}_{2}{ }^{--}$radical scavenging ability than other studied genotypes (Nidhi, 15.24\%).

$\mathrm{H}_{2} \mathrm{O}_{2}$ produced is further reduced to $\mathrm{H}_{2} \mathrm{O}$ by two major antioxidative enzymes -CAT and GPX. CAT activity increased with increase in PEG stress and was found to be 1.7-fold induced in Sreedhara at higher stress conditions; showing its efficiency in reducing the toxic effects of generated $\mathrm{H}_{2} \mathrm{O}_{2}$. Our previous study also showed an increase in CAT activity under PEG induced osmotic stress in $\operatorname{taro}^{29}$. We have also observed a significant increment in the activity of $\mathrm{H}_{2} \mathrm{O}_{2}$ scavenging enzyme GPX in Sreedhara (upto 7.8-fold change) at higher stress. This can be correlated with in situ DAB staining data; where very less brown stain was observed in Sreedhara leaves restricted at the edges only. This enhanced activity could explain the detoxification of $\mathrm{H}_{2} \mathrm{O}_{2}$ mainly occurred through GPX than CAT. Therefore, from our results it is apparent that GPX plays a stringent role in $\mathrm{H}_{2} \mathrm{O}_{2}$ elimination than CAT in Chinese potato. The genotype Sreedhara performed better by registering maximum fold change in these enzyme activities. Previous report showed enhanced activity of GPX was greatly associated with prolonged drought spell in wheat varieties ${ }^{35}$.

Our results also showed that ascorbate-glutathione cycle (ASA-GSH) played an important role on scavenging the over production of $\mathrm{H}_{2} \mathrm{O}_{2}$ due to osmotic stress in Chinese potato genotypes. APX, GR, MDAR and DHAR involved in ASA-GSH cycle were also higher in stressed plants than that in control ${ }^{39,41}$. This series of enzymatic and non-enzymatic antioxidants such as SOD, CAT, GPX and DHAR delays leaf senescence induced by PEG stress $^{42}$.

ASA acts as an important defensive antioxidant against overproduction of ROS induced by oxidative stress ${ }^{43,44}$. Resistant varieties maintained higher ascorbate content over susceptible ones under different levels of drought 
stress $^{39}$. This antioxidant plays a major role either in preventing or in lowering the risk caused by ROS in higher plants; by removal of $\mathrm{H}_{2} \mathrm{O}_{2}$ via ASA-GSH cycle. Reduced glutathione also participated in ROS inhibition and induced drought stress in Arabidopsis plants ${ }^{45}$. In our study, the magnitude of increase in these two antioxidants was lower in Nidhi than Subala and Sreedhara; showing the inability of Nidhi to cope up with induced oxidative stress and making it as susceptible.

\section{Conclusions}

In vitro PEG mediated osmotic stress resulted in oxidative burst as evident by accumulation of $\mathrm{H}_{2} \mathrm{O}_{2}$ and lipid peroxidation. Increment in enzymatic and non-enzymatic antioxidants under stress implied a positive hallmark of stress tolerance in the present study. Enhancement in the accumulation of ascorbic acid and reduced glutathione accompanied by increased GR activity depicts the involvement of ASA-GSH cycle in osmotic stress tolerance in Chinese potato. Of the five genotypes tested, Sreedhara and Subala exhibited distinct antioxidative mechanisms for scavenging of ROS and protecting the plants from deleterious effects of PEG mediated osmotic stress. Considering all the above data, our study revealed that Sreedhara and Subala were tolerant, TVM and CO-1 were moderately tolerant and Nidhi was susceptible to PEG stress. The detailed information on ROS scavenging machineries would be useful for intensification of breeding strategies in Chinese potato for development of tolerant lines to harsh environments.

Received: 23 October 2019; Accepted: 2 March 2020;

Published online: 25 March 2020

\section{References}

1. PROTA (Plant Resources of tropical Africa) Solenostemon rotundifolius Poir. (Synonyms: Germania rotondifolius Poir, Plectranthus roundifolius Sims) database.PROTA.org/db/w-wpd/exec/db (2013).

2. Hamed, K. B. et al. Physiological response of halophytes to multiple stresses. Func. Plant. Biol. 40, 883-896, https://doi.org/10.1071/ FP13074 (2013).

3. Ruttanaprasert, R. et al. Effects of water stress on total biomass, tuber yield, harvest index and water use efficiency in Jerusalem artichoke. Agric. Water Manag. 166, 130-138, https://doi.org/10.1016/j.agwat.2015.12.022 (2016).

4. Bajji, M., Lutts, S. \& Kinet, J. M. Physiological changes after exposure to and recovery from polyethylene glycol-induced water deficit in callus cultures issued from durum wheat (Triticum durum Desf.) cultivars differing in drought resistance. J Plant Physiol 156, 75-83, https://doi.org/10.1016/S0176-1617(00)80275-8 (2000).

5. Osmolovskaya, N. et al. Methodology of drought stress research: Experimental setup and physiological characterization. Int. J. Mol. Sci. 19, 4089, https://doi.org/10.3390/ijms19124089 (2018).

6. Gill, S. S. \& Tuteja, N. Reactive oxygen species and antioxidant machinery in abiotic stress tolerance in crop plants. Plant. Physiol. Biochem. 48, 909-930, https://doi.org/10.1016/j.plaphy.2010.08.016 (2010).

7. Reddy, A. R., Chaitanya, K. V. \& Vivekanandan, M. Drought-induced responses of photosynthesis and antioxidant metabolism in higher plants. J. Plant. Physiol. 161, 1189-1202, https://doi.org/10.1016/j.jplph.2004.01.013 (2004).

8. Alscher, R. G., Erturk, N. \& Heath, L. S. Role of superoxide dismutases (SODs) in controlling oxidative stress in plants. J. Exp. Bot. 53, 1331-1341, https://doi.org/10.1093/jxb/53.372.1331 (2002).

9. Møller, I. M., Jensen, P. E. \& Hansson, A. Oxidative modifications to cellular components in plants. Annu. Rev. Plant. Biol. 58, 459-481, https://doi.org/10.1146/annurev.arplant.58.032806.103946 (2007).

10. Türkan, I., Bor, M., Özdemir, F. \& Koca, H. Differential responses of lipid peroxidation and antioxidants in the leaves of drought-tolerant $P$. acutifolius Gray and drought-sensitive $P$. vulgaris L. subjected to polyethylene glycol mediated water stress. Plant. Sci. 168, 223-231, https://doi.org/10.1016/j.plantsci.2004.07.032 (2005).

11. Murashige, T. \& Skoog, F. A revised medium for rapid growth and bio assays with tobacco tissue cultures. Physiol Plant 15, 473-497, https://doi.org/10.1111/j.1399-3054.1962.tb08052.x (1962).

12. Velikova, V., Yordanov, I. \& Edreva, A. Oxidative stress and some antioxidant systems in acid rain-treated bean plants. Plant Sci 151, 59-66, https://doi.org/10.1016/s0168-9452(99)00197-1 (2000).

13. Thordal-Christensen, H., Zhang, Z., Wei, Y. \& Collinge, D. B. Subcellular localization of $\mathrm{H}_{2} \mathrm{O}_{2}$ in plants. $\mathrm{H}_{2} \mathrm{O}_{2}$ accumulation in papillae and hypersensitive response during the barley-powdery mildew interaction. Plant J 11, 1187-1194, https://doi.org/10.1046/ j.1365-313X.1997.11061187.x (1997).

14. Buege, J. A. \& Aust, S. D. Microsomal lipid peroxidation. Methods Enzymol 52, 302-310, https://doi.org/10.1016/S00766879(78)52032-6 (1978).

15. Du, Z. \& Bramlage, W. J. Modified thiobarbituric acid assay for measuring lipid oxidation in sugar-rich plant tissue extracts. J. Agric. Food Chem. 40, 1566-1570, https://doi.org/10.1021/jf00021a018 (1992).

16. Giannopolitis, C. \& Ries, S. Superoxide dismutases: I. Occurrence in higher plants. Plant. Physiol. 59, 309-314, https://doi. org/10.1104/pp.59.2.309 (1977).

17. Aebi, H. E. In Methods of Enzymatic Analysis 2, 273-286, (Academic press, 1983).

18. Urbanek, H., Kuzniak-Gebarowska, E. \& Herka, K. Elicitation of defence responses in bean leaves by Botrytis cinerea polygalacturonase. Acta Physiol. Plant. 13, 43-50 (1991).

19. Nakano, Y. \& Asada, K. Hydrogen peroxide is scavenged by ascorbate-specific peroxidase in spinach chloroplasts. Plant. Cell Physiol. 22, 867-880, https://doi.org/10.1093/oxfordjournals.pcp.a076232 (1981).

20. Hossain, M. A. \& Asada, K. Inactivation of ascorbate peroxidase in spinach chloroplasts on dark addition of hydrogen peroxide: its protection by ascorbate. Plant. Cell Physiol. 25, 1285-1295, https://doi.org/10.1093/oxfordjournals.pcp.a076837 (1984).

21. Krivosheeva, A. et al. Cold acclimation and photoinhibition of photosynthesis in Scots pine. Planta 200, 296-305, https://doi. org/10.1007/BF00200296 (1996).

22. Cakmak, I., Strbac, D. \& Marschner, H. Activities of hydrogen peroxide-scavenging enzymes in germinating wheat seeds. J. Exp. Bot. 44, 127-132, https://doi.org/10.1093/jxb/44.1.127 (1993).

23. Mukherjee, S. P. \& Choudhuri, M. A. Implications of water stress-induced changes in the levels of endogenous ascorbic acid and hydrogen peroxide in Vigna seedlings. Physiol Plant 58, 166-170, https://doi.org/10.1111/j.1399-3054.1983.tb04162.x (1983).

24. Moron, M. S., Depierre, J. W. \& Mannervik, B. Levels of glutathione, glutathione reductase and glutathione S-transferase activities in rat lung and liver. BBA - Gen Subj 582, 67-78, https://doi.org/10.1016/0304-4165(79)90289-7 (1979).

25. Gomez, K. A. \& Gomez, A. A. Statistical Procedures For Agricultural Research. (John Wiley Sons Inc, 1984).

26. Tukey, J. W. Comparing individual means in the analysis of variance. Biometrics 5, 99-114, https://doi.org/10.2307/3001913 (1949).

27. Gopal, J. \& Iwama, K. In vitro screening of potato against water-stress mediated through sorbitol and polyethylene glycol. Plant Cell Rep 26, 693-700, https://doi.org/10.1007/s00299-006-0275-6 (2007). 
28. Albiski, F., Najla, S., Sanoubar, R., Alkabani, N. \& Murshed, R. In vitro screening of potato lines for drought tolerance. Physiol Mol Biol Plants 18, 315-321, https://doi.org/10.1007/s12298-012-0127-5 (2012).

29. Sahoo, M. R., Dasgupta, M. \& Mukherjee, A. Effect of in vitro and in vivo induction of poltethylene glycol mediated osmotic stress on hybrid taro (Colocasia esculenta (L.) Schott). Ann. Trop. Res. 28(2), 1-11 (2006).

30. Hussain, M., Malik, M. A., Farooq, M., Ashraf, M. Y. \& Cheema, M. A. Improving drought tolerance by exogenous application of glycinebetaine and salicylic acid in sunflower. J Agron Crop Sci 194, 193-199, https://doi.org/10.1111/j.1439-037X.2008.00305.x (2008).

31. Khaleghi, A. et al. Morphological, physiochemical and antioxidant responses of Maclura pomifera to drought stress. Sci Rep 9, 19250, https://doi.org/10.1038/s41598-019-55889-y (2019).

32. Mittler, R. Oxidative stress, antioxidants and stress tolerance. Trends Plant Sci 7, 405-410, https://doi.org/10.1016/S13601385(02)02312-9 (2002).

33. Fu, L. et al. Physiological investigation and transcriptome analysis of polyethylene glycol (Peg)-induced dehydration stress in Cassava. Int. J. Mol. Sci. 17, 283, https://doi.org/10.3390/ijms17030283 (2016).

34. Yang, F. \& Miao, L. F. Adaptive responses to progressive drought stress in two poplar species originating from different altitudes. Silva Fenn. 44, 23-37, https://doi.org/10.14214/sf.160 (2010).

35. Chakraborty, U. \& Pradhan, B. Oxidative stress in five wheat varieties (Triticum aestivum L.) exposed to water stress and study of their antioxidant enzyme defense system, water stress responsive metabolites and $\mathrm{H}_{2} \mathrm{O}_{2}$ accumulation. Brazilian J. Plant Physiol 24(2), 117-130, https://doi.org/10.1590/S1677-04202012000200005 (2012).

36. Kabiri, R., Nasibi, F. \& Farahbakhsh, H. Effect of exogenous salicylic acid on some physiological parameters and alleviation of drought stress in Nigella sativa plant under hydroponic culture. Plant Prot Sci 50, 43-51, https://doi.org/10.17221/56/2012-pps (2014).

37. Pérez-Clemente, R. M. et al. Biotechnological approaches to study plant responses to stress. Bio Med Res Int 2013, https://doi. org/10.1155/2013/654120 (2013).

38. Khanna-Chopra, R. \& Selote, D. S. Acclimation to drought stress generates oxidative stress tolerance in drought-resistant than susceptible wheat cultivar under field conditions. Env. Exp. Bot. 60, 276-283, https://doi.org/10.1016/j.envexpbot.2006.11.004 (2007).

39. Wang, X. et al. Differential activity of the antioxidant defence system and alterations in the accumulation of osmolyte and reactive oxygen species under drought stress and recovery in rice (Oryza sativa L.) tillering. Sci. Rep 9, 8543, https://doi.org/10.1038/s41598019-44958-x (2019).

40. Wang, Y., Branicky, R., Noë, A. \& Hekimi, S. Superoxide dismutases: Dual roles in controlling ROS damage and regulating ROS signaling. J. Cell Biol. 217(6), 1915-1928, https://doi.org/10.1083/jcb.201708007 (2018).

41. Hasanuzzaman, M. et al. Regulation of ascorbate-glutathione pathway in mitigating oxidative damage in plants under abiotic stress. Antioxidants 8(9), 384, https://doi.org/10.3390/antiox8090384 (2019).

42. Lai, Qxian et al. Effects of osmotic stress on antioxidant enzymes activities in leaf discs of PSAG12-IPT modified Gerbera. $J$. Zhejiang Univ. Sci. B 8, 458-464, https://doi.org/10.1631/jzus.2007.B0458 (2007).

43. Yang, Y., Han, C., Liu, Q., Lin, B. \& Wang, J. Effect of drought and low light on growth and enzymatic antioxidant system of Picea asperata seedlings. Acta Physiol Plant 30, 433-440, https://doi.org/10.1007/s11738-008-0140-z (2008).

44. Wang, Z., Xiao, Y., Chen, W., Tang, K. \& Zhang, L. Increased vitamin C content accompanied by an enhanced recycling pathway confers oxidative stress tolerance in Arabidopsis. J Integr Plant Biol 52, 400-409, https://doi.org/10.1111/j.1744-7909.2010.00921.x (2010).

45. Chen, J. H. et al. Drought and salt stress tolerance of an Arabidopsis glutathione S-transferase U17 knockout mutant are attributed to the combined effect of glutathione and abscisic acid. Plant. Physiol. 158, 340-351, https://doi.org/10.1104/pp.111.181875 (2012).

\section{Acknowledgements}

The financial support of ICAR Research Complex for North Eastern Hill Region, Meghalaya, India under the institutional project ID-IXX10691 is greatly acknowledged. We also acknowledge our sincere thanks to Head, ICAR-RCCTCRI, Bhubaneswar, India for sharing the planting material of Chinese potato.

\section{Author contributions}

M.R.S. and M.D. participated in conceiving, designing the experiment, analyzing the data and drafted the manuscript. T.R.D. and M.D. executed the experiments. All authors (P.N. and N.P.) have viewed and approved the present form of the manuscript.

\section{Competing interests}

The authors declare no competing interests.

\section{Additional information}

Correspondence and requests for materials should be addressed to M.R.S.

Reprints and permissions information is available at www.nature.com/reprints.

Publisher's note Springer Nature remains neutral with regard to jurisdictional claims in published maps and institutional affiliations.

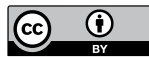

Open Access This article is licensed under a Creative Commons Attribution 4.0 International License, which permits use, sharing, adaptation, distribution and reproduction in any medium or format, as long as you give appropriate credit to the original author(s) and the source, provide a link to the Creative Commons license, and indicate if changes were made. The images or other third party material in this article are included in the article's Creative Commons license, unless indicated otherwise in a credit line to the material. If material is not included in the article's Creative Commons license and your intended use is not permitted by statutory regulation or exceeds the permitted use, you will need to obtain permission directly from the copyright holder. To view a copy of this license, visit http://creativecommons.org/licenses/by/4.0/.

(C) The Author(s) 2020 